Rev. Bras. Saúde Prod. Anim., Salvador, v.17, n.2, p.174-185 abr./jun., 2016 http://www.rbspa.ufba.br

\title{
Parâmetros sanguíneos de vacas leiteiras mantidas em pasto suplementadas com diferentes fontes proteicas
}

\section{Blood parameters of grazing dairy cows supplemented with different protein sources}

\author{
SILVA, Joelson Antonio $^{1}{ }^{*}$; PEREIRA NETO, Wlademiro Silvano ${ }^{1}$; RIBEIRO, \\ Marinaldo Divino ${ }^{1}$; LEONEL, Fernando de Paula ${ }^{2}$; PAULA, Nelcino Francisco de ${ }^{1}$; \\ FAZZION, Josimara Cristina ${ }^{2}$; MALHADO, Anna Luz Netto ${ }^{1}$; BARROS, Marcel \\ Pereira $^{3}$, CABRAL, Luciano da Silva ${ }^{1}$, SOUZA, Édila Cristina de ${ }^{1}$
}

\author{
${ }^{1}$ Universidade Federal de Mato Grosso, Faculdade de Agronomia, Medicina Veterinária e Zootecnia, \\ Cuiabá, Mato Grosso, Brasil. \\ ${ }^{2}$ Universidade Federal de São João Del Rei, Departamento de Zootecnia, São João Del Rei, Minas \\ Gerais, Brasil. \\ ${ }^{3}$ Universidade de Cuiabá, Faculdade de Medicina Veterinária, Cuiabá, Mato Grosso, Brasil. \\ *Endereço para correspondência: joelson.silva@hotmail.com
}

\section{RESUMO}

Objetivou-se com este trabalho avaliar o efeito da suplementação com diferentes fontes proteicas na dieta de vacas leiteiras mantidas em pastagem de Brachiaria brizantha MG5 sobre os níveis séricos de glicose, triglicerídeos, colesterol e ureia e das enzimas gama glutamina transferase, creatina quinase e aminotransferase. Avaliaram-se diferentes fontes proteicas: coproduto de feijão, farelo de soja, farelo de girassol e farelo de algodão. Foram utilizadas 8 vacas cruzadas 5/8 (Holandês x Gir), peso médio $500 \pm 60,33 \mathrm{~kg}$, produção média de leite de $14,85 \pm 3,28 \mathrm{~kg} / \mathrm{dia}$, entre 60 e 90 dias de lactação, em delineamento quadrado latino 4 x 4 duplo e simultâneo. Cada período experimental teve duração de 15 dias, sendo 10 dias iniciais para adaptação dos animais e os demais para avaliação e coleta de dados. Houve efeito de interação $(\mathrm{P}<0,05)$ das fontes proteicas e tempos de coleta sobre os níveis séricos de glicose. Não houve efeito $(\mathrm{P}>0,05)$ das fontes proteicas para os valores de triglicerídeos, colesterol e ureia dos animais, com média de $6,46 \pm 2,05 ; 182,43 \pm 37,52$ e $38,20 \pm 12,29 \mathrm{mg} / \mathrm{dL}$, respectivamente. Houve efeito $(\mathrm{P}<0,05)$ dos tempos de coleta nos níveis sanguíneos de triglicerídeos e ureia. As diferentes fontes proteicas também não influenciaram $(\mathrm{P}>0,05)$ os níveis séricos das enzimas gama glutamina transferase, creatina quinase $\mathrm{e}$ aminotransferase, com médias de 26,76 $\pm 8,02$; $112,13 \pm 31,72$ e $58,79 \pm 20,13 \quad \mathrm{UI} / \mathrm{L}$, respectivamente. As fontes proteicas promoveram alterações na glicemia com os tempos de coletas, sendo que estes alteraram os valores de triglicerídeos e ureia. Não foram observadas alterações para os demais metabólitos sanguíneos.

Palavras-chave: bovinos de leite, forragem, suplementação

\section{SUMMARY}

The present work aimed to evaluate the effect of supplementation with different protein sources in the diets for dairy cows kept on Brachiaria brizantha MG5 grass pasture on serum levels of the glucose, triglycerides, cholesterol and urea as well as on enzymes gama grutamil transferase, creatinine quinase and aminotransferase. We have evaluated the following protein sources: bean byproduct, soybean meal, sunflower meal and cottonseed meal. Eight crossbred cows (Holstein x Gir) were used, weighing $500 \pm 60.33$ $\mathrm{kg}$, average milk production of $14.85 \pm 3.28$ $\mathrm{kg}$ /day, between the 60th and the 90th day of calving, by a simultaneous double $4 \times 4$ latin square design $4 \times 4$. Each experimental period lasted 15 days, of which the first 10 days were designed to animal adaptation and the final five days for data collection. There was an interaction effect $(\mathrm{P}<0.05)$ among protein sources and sampling time on serum glucose. There was no 
effect $(\mathrm{P}>0.05)$ of protein sources for the triglycerides, cholesterol and urea levels, averaging $\quad 6.46 \pm 2.05, \quad 182.43 \pm 37.52$ and $38.20 \pm 12.29 \mathrm{mg} / \mathrm{dL}$, respectively. There was a significant effect $(\mathrm{P}<0.05)$ of the sampling time on blood levels of triglycerides and urea. The different protein sources did not affect significantly $(\mathrm{P}>0.05)$ serum enzyme levels of glutamine transferase, creatinine quinase and aminotransferase, averaging $26.76 \pm 8.02$, $112.13 \pm 20.13$ and $58.79 \pm 31.72 \quad \mathrm{IU} / \mathrm{L}$, respectively. The protein sources promoted changes on blood glucose with the sampling time, while sampling time altered triglycerides and urea levels. Changes to other blood metabolites were not observed.

Keywords: forage, milk cattle, supplementation

\section{INTRODUÇÃO}

O estudo do perfil dos metabólitos sanguíneos nos animais de produção é importante para diagnosticar e prevenir transtornos do metabolismo, sendo utilizado também, através dos seus parâmetros normais, como indicador do seu estado nutricional (HAIDA et al., 1996).

A composição bioquímica do sangue reflete o equilíbrio entre o ingresso, 0 egresso e a metabolização dos nutrientes nos tecidos animais. Assim, a quebra da homeostase pode levar a diminuição do desempenho zootécnico, transtornos digestivos e doenças metabólicas. Assim, a avaliação e interpretação dos componentes químicos do sangue são úteis para diagnosticar desequilíbrios de origem metabólica ou nutricional (GONZÁLEZ, 2009).

Os principais metabólitos associados ao balanço energético são ácidos graxos não esterificados, $\beta$-hidroxibutirato, glicose, colesterol e triglicerídeos. Outro importante componente sanguíneo é a ureia (AEBERHARD et al., 2001). Nível adequado de ureia sanguínea é um indicador do correto balanceamento entre a proteína e carboidratos fermentescíveis, pois a assincronia entre esses nutrientes podem elevar a concentração de ureia no sangue, excreção no leite e na urina, consequentemente perda de um dos nutrientes mais onerosos da dieta dos ruminantes (FERGUSON \& CHALUPA, 1989; ARRUDA et al., 2008). A avaliação destes componentes sanguíneos permite avaliar diferentes tipos de ingredientes que podem ser utilizados na dieta dos animais, visto que diferenças nas suas digestibilidades incorrem em diferentes concentrações sanguíneas dos metabólitos citados acima.

$\mathrm{O}$ correto e adequado funcionamento hepático se faz necessário para a metabolização dos ingredientes oriundos do processo digestivo. A avaliação da atividade hepática, com o objetivo de avaliar distúrbios metabólicos, pode ser realizada através da verificação dos níveis sanguíneos das enzimas aspartato aminotransferase, gama glutamiltransferase e fosfatase alcalina e as alterações musculares são bem definidas bioquimicamente pela mensuração de creatina quinase, uma enzima específica do músculo esquelético (MUNDIM, et al., 2007). De qualquer forma, como nos ruminantes a síntese de glicose depende de um adequado funcionamento hepático, o mais racional a fazer é avaliar o fígado mediante esses indicadores de sua função, conjuntamente com a glicose.

Nesse sentido, objetivou-se com este estudo avaliar o efeito da suplementação de vacas leiteiras mantidas a pasto com diferentes fontes proteicas sobre os parâmetros sanguíneos. 
Rev. Bras. Saúde Prod. Anim., Salvador, v.17, n.2, p.174-185 abr./jun., 2016 http://www.rbspa.ufba.br

\section{MATERIAL E MÉTODOS}

Esse trabalho foi conduzido de acordo com os princípios éticos na experimentação animal adotados pela Sociedade Brasileira de Ciência em Animais de Laboratório (SBCAL) e aprovado pelo Comitê de Ética em Pesquisa Animal (CEPA)-UFMT.

$\mathrm{O}$ experimento foi conduzido na na Fazenda Experimental Risoleta Neves, utilizada de acordo com o convênio estabelecido entre a Universidade Federal de São João Del Rei - MG (UFSJ) e a Empresa de Pesquisa Agropecuária de Minas Gerais (EPAMIG), no período entre Fevereiro e Abril de 2012.

Foram utilizadas 8 vacas cruzadas $5 / 8$ Holandês x Gir), com peso médio de $500 \pm 60,33 \mathrm{~kg}$, produção média de leite de $14,85 \pm 3,28 \mathrm{~kg} / \mathrm{dia}$, entre o $60^{\circ}$ e o $90^{\circ}$ dia de lactação, mantidas em sistema de pastejo rotacionado constituídos de
Brachiaria brizanta cv. MG5, providos de bebedouros e saleiros.

Os animais foram agrupados em 2 quadrados latinos simultâneos, cada um com 4 animais, submetidos a 4 tratamentos em 4 períodos experimentais. Cada período experimental teve duração de 15 dias, dos quais os 10 primeiros foram destinados à adaptação às dietas $\mathrm{e}$ os demais para coleta de dados.

Os tratamentos foram constituídos por suplementos contendo diferentes fontes proteicas. Os alimentos utilizados como fonte de proteína na alimentação foram: coproduto de feijão (SPF), farelo de soja (SPS), farelo de girassol (SPG) e farelo de algodão (SPA). Os suplementos experimentais foram formulados a fim de serem isonitrogenados com $22 \%$ de $\mathrm{PB}$ (NRC, 2001) e ofertados duas vezes ao dia (06h30 e 15h00). Os ingredientes utilizados na formulação dos suplementos foram: milho moído, os alimentos proteicos supracitados, fosfato bicálcico, ureia e calcário calcítico (Tabela 1).

Tabela 1. Composição dos suplementos expressos na base de matéria seca (\%MS)

\begin{tabular}{lcccc}
\hline \multirow{2}{*}{ Ingredientes } & \multicolumn{4}{c}{ Fontes Proteicas } \\
\cline { 2 - 5 } & Feijão & Soja & Girassol & Algodão \\
\hline Coproduto de feijão & 44,23 & - & - & - \\
Farelo de soja & - & 23,08 & - & - \\
Farelo de algodão & - & - & - & 26,93 \\
Farelo de Girassol & - & - & 33,16 & - \\
Farelo de milho & 53,44 & 74,04 & 64,22 & 70,57 \\
Ureia & 0,15 & 0,10 & 0,13 & 0,12 \\
Fosfato bicálcico & 0,78 & 1,06 & 1,03 & 0,46 \\
Calcário calcítico & 1,55 & 1,83 & 1,59 & 2,04 \\
\hline \multicolumn{5}{c}{ Consumo estimado (kg/animal/dia) } \\
\hline Suplemento (MS) & 7,10 & 6,73 & 6,98 & 7,10 \\
Forragem (MS) & 8,98 & 8,98 & 8,98 & 8,98 \\
\hline
\end{tabular}

Os registros das condições climáticas no local do experimento foram obtidos da estação meteorológica localizada na Fazenda Experimental. Foi observada temperatura média de $24,0^{\circ} \mathrm{C}$ e umidade relativa do ar de $67,2 \%$.

As coletas de sangue foram realizadas no $15^{\circ}$ dia de cada período. A primeira coleta foi realizada antes do consumo de suplemento da manhã e as outras três 
Rev. Bras. Saúde Prod. Anim., Salvador, v.17, n.2, p.174-185 abr./jun., 2016 http://www.rbspa.ufba.br

coletas com intervalos de duas horas $(2$, 4, 6) a partir do consumo de suplemento, totalizando 4 amostras por animal a cada período experimental.

As amostras foram colhidas por punção na veia coccígea, em que a glicose foi dosada imediatamente após a coleta, com o uso de glicosímetro portátil comercial (ACCU-CHEK Active $\circledR$ ), conforme orientações fornecidas pelo fabricante.

Para realização das demais análises dos parâmetros sanguíneos foram armazenados soros de acordo com a recomendação de cada kit comercial. Foram realizadas análises de triglicerídeos (Triglicérides Liquiform Labtest Diagnóstica - Ref. 87), colesterol (Colesterol Liquiform Labtest Diagnóstica - Ref. 76), ureia (Ureia UV Liquiform Labtest Diagnóstica - Ref. 104), gama glutamina transferase (Gama GT Liquiform Labtest Diagnóstica Ref. 105), creatina quinase (CK-NAC Liquiform Labtest Diagnóstica - Ref. 117) e aspartato aminotransferase (AST/GOT Liquiform Labtest Diagnóstica - Ref. 109). As leituras foram realizadas em analisador bioquímico automático Labmax Plenno (Labtest Diagnóstica S.A.).

Os parâmetros estudados foram analisados considerando um delineamento em quadrado latino duplo simultâneo. Utilizou-se o procedimento MIXED do SAS, versão 9.3. As variáveis foram interpretadas como medidas repetidas no tempo com os efeitos fixos de tratamento, tempo de coleta e o efeito de interação tratamento*tempo. Animal dentro de quadrado latino, período e quadrado latino foram incluídos no modelo como efeito aleatório. Para a análise, estruturas de matriz de covariância dos erros foram ajustadas. Dentre todas as estruturas investigadas, TOEPLITZ BANDED foi a melhor conforme o critério de informação bayesiano, a qual foi também utilizada para os modelos subsequentes. A opção LSMEANS foi utilizada para gerar as médias individuais para cada tratamento, tempo e interação. Os efeitos principais e interação foram definidos pelo teste-F da ANOVA, sendo o comando SLICE usado para separar interações significativas. Contrastes ortogonais foram utilizados para partição específica dos efeitos de tempo de coleta dentro de cada tratamento em efeito de ordem linear, quadrático e cúbico. Efeitos foram declarados significativos quando $\mathrm{P}<0,05$.

\section{RESULTADOS E DISCUSSÃO}

Houve efeito de interação entre os suplementos e tempos de coletas $(\mathrm{P}<0,05)$ sobre os níveis séricos de glicose para os diferentes tratamentos utilizados (Tabela 2).

Tabela 2. Médias de mínimos quadrados de concentrações séricas de glicose de vacas leiteiras mantidas a pasto suplementadas com concentrados contendo diferentes fontes proteicas

\begin{tabular}{lcccccccc}
\hline \multirow{2}{*}{ Variáveis } & \multicolumn{4}{c}{ Suplementos* } & \multirow{2}{*}{ EPM } & \multicolumn{3}{c}{ Valor P } \\
\cline { 2 - 4 } & SPF & SPS & SPG & SPA & & Trat. & Tempo & Trat**Tempo \\
\hline Glicose $(\mathrm{mg} / \mathrm{dL})$ & 52,03 & 46,91 & 52,78 & 51,28 & 1,73 & 0,006 & 0,545 & 0,004 \\
\hline
\end{tabular}

"Suplementos: SPF= resíduo de feijão; SPS= farelo de soja; $\mathrm{SPG}=$ farelo de girassol e SPA= farelo de Algodão 38\% (PB).

$\mathrm{EPM}=$ erro padrão da média. 
Rev. Bras. Saúde Prod. Anim., Salvador, v.17, n.2, p.174-185 abr./jun., 2016 http://www.rbspa.ufba.br

Para o suplemento farelo de soja foi observado efeito cúbico $(\mathrm{P}<0,05)$ em função dos tempos de coleta (Figura 1), possivelmente relacionado ao perfil e taxa de degradação dos seus nutrientes. O farelo de soja possui $64,98 \%$ de proteína degradada no rúmen (PDR) em relação ao seu teor de proteína bruta (CQBAL, 2015), apresentando 22,3 e 77,7\% de frações "a" e "b" da proteína bruta (MARTINS et al., 1999). Assim, pode-se relacionar o comportamento cúbico dos valores de glicose sanguínea observada em função dos tempos de coletas ao consumo de concentrado contendo a fonte proteica citada. Com o consumo de concentrado após a ordenha da manhã observa-se aumento dos valores de glicose com o decorrer do tempo. Isso pode estar relacionado à degradação das frações proteicas, resultando em maiores degradações da matéria seca e consequente maior produção de propionato no rúmen, principal precursor de gliconeogênese hepática (VAN SOEST, 1994). Aproximadamente $85 \%$ da glicose circulante nos ruminantes tem origem na gliconeogênese hepática (MARQUES et al., 2011), assim seu comportamento em relação aos tempos de coleta está relacionado de forma direta a produção de seu precursor no rúmen.

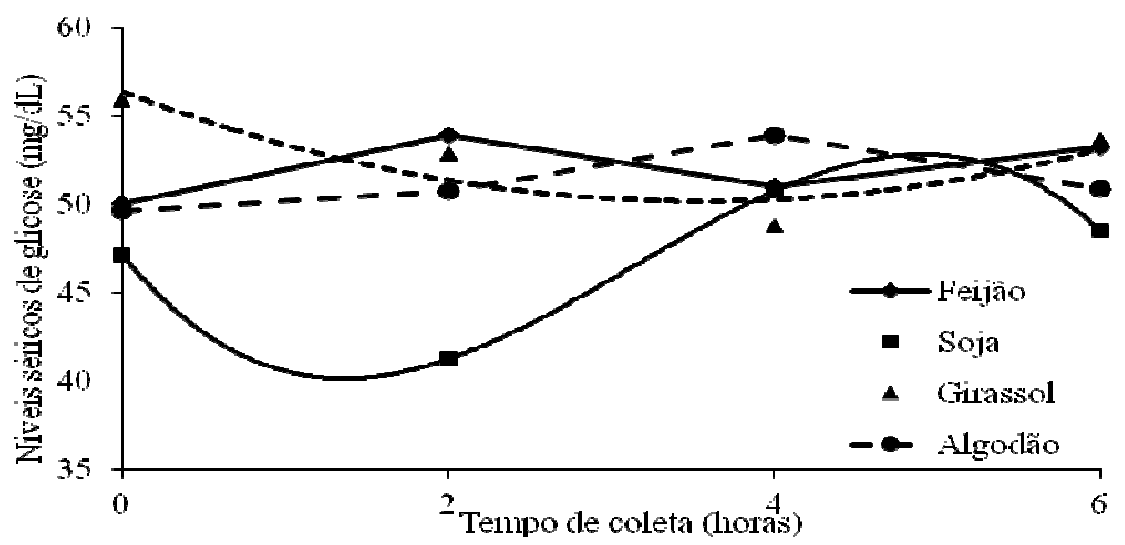

Figura 1. Glicose sérica $(\mathrm{mg} / \mathrm{dL})$ de vacas leiteiras mantidas a pasto suplementadas com diferentes fontes proteicas em função dos tempos de coleta

Ao analisar o suplemento contendo farelo de girassol observa-se efeito quadrático $(\mathrm{P}<0,05$; Figura 1$)$. Isso provavelmente está relacionado à taxa de degradação ao longo do tempo dos seus nutrientes. O farelo de girassol possui $86,07 \%$ de proteína degradada no rúmen (PDR) em relação ao seu teor de proteína bruta (CQBAL, 2015), possuindo 54,57 e 45,22\% de fração "a" e "b" da proteína bruta, respectivamente (MARCONDES et al., 2009). Possivelmente, essas proporções das frações proteicas promoveram a variação nos valores de glicose observada para este alimento na Figura 1.

Para a coleta antes do consumo dos concentrados experimentais foram observados menor valor, maior valor e média glicêmica de 37; 68 e $50,66 \mathrm{mg} / \mathrm{dL}$, respectivamente. No tempo de coleta 2 horas se observaram menor valor, maior valor e média glicêmica de $33 ; 65$ e 49,69mg/dL, respectivamente. No tempo 4 horas foram observados menor valor, maior valor e média 
glicêmica de 42; 65 e 51,09mg/dL, respectivamente, e no tempo 6 foram encontrados menor valor, maior valor e média glicêmica de 41; 66 e $51,56 \mathrm{mg} / \mathrm{dL}$, respectivamente. As médias observadas em todos os tempos de coleta estão de acordo com o intervalo de 39,42 a $83,10 \mathrm{mg} / \mathrm{dL}$ observados em diversos estudos com vacas leiteiras (WITTWER, 2000; ALVES et al., 2004; CAMPOS et al., 2007; PEDROSO et al., 2007; POGLIANI \& BIRGEL JÚNIOR, 2007; ARRUDA et al., 2008; NIKKHAH et al., 2008; GANDRA et al., 2009; LOHRENZ et al., 2010; MARQUES et al., 2010; GONZÁLEZ et al., 2011; MARQUES et al., 2011). Esta constatação se torna importante à medida que estas fontes proteicas podem ser recomendadas para uso nas dietas sem alteração do aporte de precursores para síntese do leite e supostamente o volume de leite produzido pelos animais. Quando se analisa os menores e maiores valores, somente os tempos 0 e 2 horas apresentaram menores valores a baixo do intervalo encontrado nos estudos supracitados. Isso pode estar relacionado a diferenças nos valores de glicemia observadas nos animais utilizados no estudo.

Para avaliação dos níveis glicêmicos foi utilizado glicosímetro portátil. Ao se comparar os dados obtidos a partir deste equipamento com as literaturas citadas acima é possível observar a possibilidade de sua utilização na mensuração da glicemia em vacas leiteiras de forma ágil, prática e confiável. Alguns estudos já foram realizados e verificaram semelhança entre os resultados de glicemia para animais através do método enzimático colorimétrico e obtidos através de glicosímetro portátil (CAMACHO, et al., 2012; POSSAMAI et al. 2013). Vale ressaltar que a dosagem de glicose requer cuidados, especialmente em relação ao tempo gasto entre o momento da coleta, centrifugação e análise das amostras. Sendo assim, agilidade e praticidade do uso de glicosímetros portáteis na obtenção dos resultados pode evitar que a glicose disponível continue sendo degradada pelos eritrócitos, leucócitos e plaquetas gerando resultados mais confiáveis (CAMPOS, et al., 2007; POSSAMAI et al., 2013).

Não foram observados efeitos de interação $(\mathrm{P}>0,05)$ e das diferentes fontes proteicas nos níveis sanguíneos de triglicerídeos, com média de $6,46 \pm 2,05 \mathrm{mg} / \mathrm{dL}$ (Tabela 3). Em estudo realizado com níveis de resíduo de feijão na dieta de vacas leiteiras Fonseca et al. (2016) observaram efeito linear crescente da sua inclusão, com valores de 20,$66 ; 22,18 ; 24,69$ e $24,44 \mathrm{mg} / \mathrm{dL}$. Os valores observados neste estudo estão a baixo dos valores de triglicerídeos normais de 14,9 a $24,0 \mathrm{mg} / \mathrm{dL}$ citado por Pogliani \& Birgel Júnior (2007). Provavelmente estes menores valores de triglicerídeos podem estar relacionados com a menor ingestão de gordura na dieta ou os animais estarem em final de provável balanço energético negativo em decorrência de estarem entre a $8^{\mathrm{a}}$ e $13^{\mathrm{a}}$ semana de lactação. Em estudo realizado por González et al. (2009) foi observado que em $43 \%$ das vacas com baixa lipomobilização valores de triglicerídeos inferiores a $10,6 \mathrm{mg} / \mathrm{dL}$.

Foi observado efeito quadrático dos valores sanguíneos de triglicerídeos em relação aos tempos de coleta (Figura 2). Essa variação ao longo do tempo pode estar relacionada à diferença na taxa de degradação e absorção dos seus precursores na dieta, pois sua concentração sanguínea é mantida a partir de ácidos graxos dietéticos absorvidos e transportados em lipoproteínas intestinais (FATAHNIA, et al., 2012). 
Rev. Bras. Saúde Prod. Anim., Salvador, v.17, n.2, p.174-185 abr./jun., 2016 http://www.rbspa.ufba.br ISSN 15199940

Tabela 3. Médias de mínimos quadrados de concentrações séricas de triglicerídeos, colesterol e ureia de vacas leiteiras mantidas a pasto suplementadas com concentrados contendo diferentes fontes proteicas

\begin{tabular}{lcccccccc}
\hline \multirow{2}{*}{ Variáveis } & \multicolumn{4}{c}{ Suplementos $^{*}$} & \multirow{2}{*}{ EPM } & \multicolumn{3}{c}{ Valor P } \\
\cline { 2 - 4 } & SPF & SPS & SPG & SPA & & Trat & Tempo & Trat*Tempo \\
\hline Triglicerídeos (mg/dL) & 6,34 & 5,59 & 6,08 & 6,07 & 1,06 & 0,451 & 0,001 & 0,947 \\
Colesterol (mg/dL) & 178,03 & 180,91 & 187,72 & 183,06 & 11,29 & 0,941 & 0,840 & 0,252 \\
Ureia (mg/dL) & 31,92 & 39,86 & 42,50 & 38,52 & 4,06 & 0,088 & $<0,001$ & 0,572
\end{tabular}

"Suplementos: $\mathrm{SPF}=$ resíduo de feijão; $\mathrm{SPS}=$ farelo de soja; $\mathrm{SPG}=$ farelo de girassol e SPA= farelo de Algodão 38\% (PB).

$\mathrm{EPM}=$ Erro padrão da média.

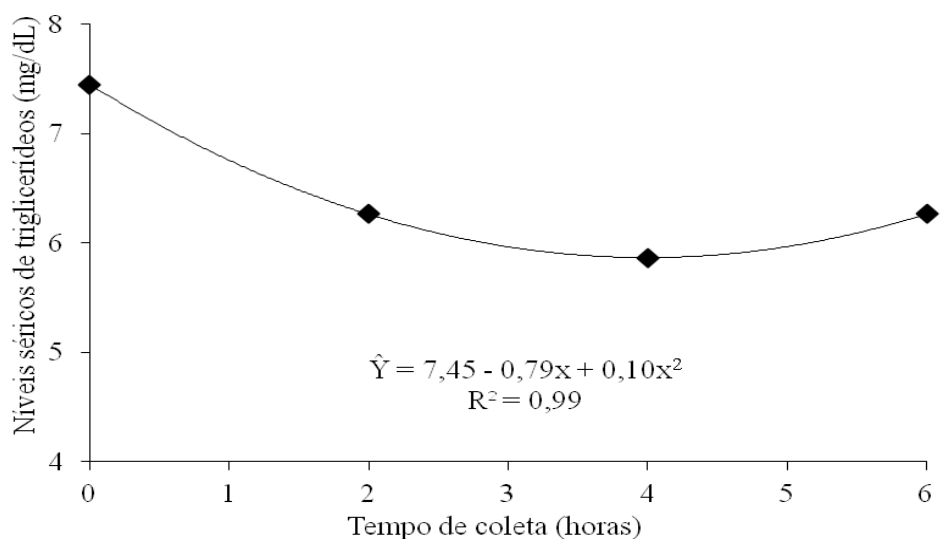

Figura 2. Médias de triglicerídeos $(\mathrm{mg} / \mathrm{dL})$ de vacas leiteiras mantidas a pasto suplementadas com diferentes fontes proteicas. 0: antes do consumo de concentrado; 2: duas horas após o consumo de concentrado; 4: quatro horas após o consumo de concentrado; 6: seis horas após o consumo de concentrado

Não houve alteração nos valores de colesterol $(\mathrm{P}>0,05)$ em função das diferentes fontes proteicas, sendo observado média de $182,43 \pm 37,52 \mathrm{mg} / \mathrm{dL}$ (Tabela 3). Esses valores estão acima das variações de 116,0 a 147,9mg/dL e 106 a $149 \mathrm{mg} / \mathrm{dL}$, citadas por Pogliani \& Birgel Júnior (2007) e González, et al. (1996), respectivamente, como valores normais para vacas leiteiras. Provavelmente esses maiores valores de colesterol podem estar relacionados ao elevado consumo de concentrado e alta proporção de carboidratos nas dietas dos animais, principalmente devido aos níveis de suplementação utilizados no estudo.

Não foram observados efeito $(\mathrm{P}>0,05)$ das diferentes fontes proteicas nos níveis sanguíneos de ureia, com média de $38,20 \pm 12,29 \mathrm{mg} / \mathrm{dL}$ (Tabela 3). Esses valores estão de acordo com o intervalo de 25 a $57 \mathrm{mg} / \mathrm{dL}$ e 15 a $40 \mathrm{mg} / \mathrm{dL}$ (GONZÁLEZ \& ROCHA, 1998; BOUDA et al., 2000), respectivamente, para vacas de leite. Níveis adequados de ureia sanguínea são indicadores do correto balanceamento entre proteína e carboidratos fermentescíveis, uma vez que as sincronias entre esses nutrientes podem elevar a concentração de ureia no 
sangue, excreção no leite e na urina, consequentemente perda de um dos nutrientes mais onerosos da dieta dos ruminantes (FERGUSON \& CHALUPA, 1989; ARRUDA et al., 2008).

As concentrações de ureia no sangue dos animais apresentaram comportamento quadrático $(\mathrm{P}<0,05)$ em função dos tempos de coleta (Figura 3). Esse comportamento dos níveis de ureia sanguínea refletem o consumo de proteína oriunda do concentrado e da forragem e sua taxa de digestão. A ureia é um indicador sensível, direto e imediato da ingestão de proteína, de forma que excedentes de proteína na dieta são refletidos por aumentos de ureia tanto no sangue quanto no leite, mesmo estando dentro de limites já citados anteriormente como normais (GONZÁLEZ, 2009).

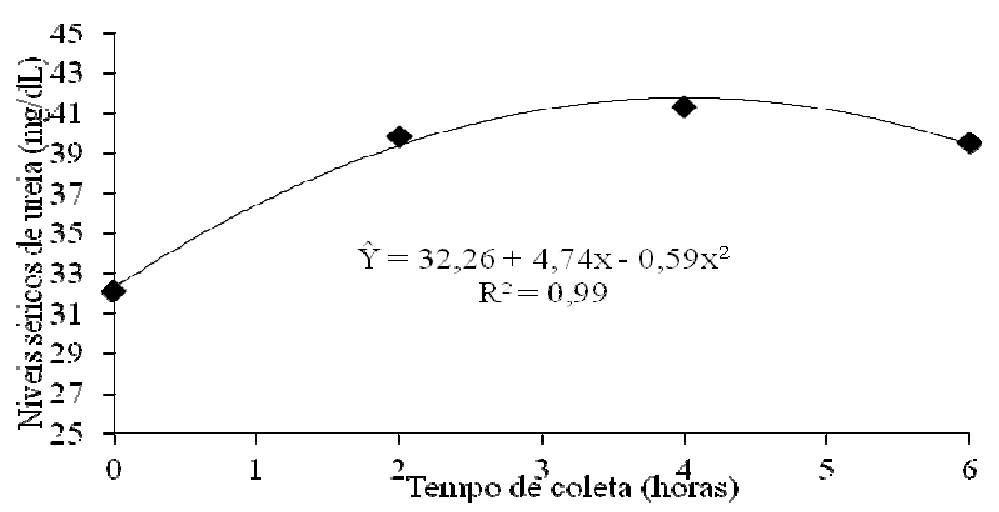

Figura 3. Médias de ureia $(\mathrm{mg} / \mathrm{dL})$ de vacas leiteiras mantidas a pasto suplementadas com diferentes fontes proteicas. 0 : antes do consumo de concentrado; 2: duas horas após o consumo de concentrado; 4: quatro horas após o consumo de concentrado; 6: seis horas após o consumo de concentrado

Não houve efeito de interação $(\mathrm{P}>0,05)$ entre as fontes proteicas utilizadas e os tempos de coleta para os níveis sanguíneos de GGT. Também não se observou efeito $(\mathrm{P}>0,05)$ das fontes proteicas nos valores de GGT com média de 26,76 $\pm 8,02 \mathrm{UI} / \mathrm{L}$ (Tabela 4). Estes valores estão dentro da variação de $11,2 \pm 0,39$ a $28,5 \pm 11,3$ observadas em diversos estudos realizados no Brasil (SOUZA, 1997; SOUZA et al., 2001). Em estudo realizado na Itália, foram observados valores de GGT semelhantes, com médias de $24 \mathrm{UI} / \mathrm{L}$ para vacas de leite em levantamento com 740 animais, clinicamente normais e classificadas como sadios em exame clínico prévio (COZZI et al., 2011).

Foi observado efeito $(\mathrm{P}<0,05)$ dos tempos de coleta nos valores de GGT, provavelmente em razão da maior demanda hepática para metabolização de nutrientes oriundos da digestão ruminal, os animais apresentaram estes valores maiores de GGT após o consumo de concentrado. Assim, podese afirmar que os estavam com a função hepática normais, uma vez que segundo Butler (2000) aumento nos valores de GGT são indicativos de lesão hepática e obstrução biliar. 
Rev. Bras. Saúde Prod. Anim., Salvador, v.17, n.2, p.174-185 abr./jun., 2016 http://www.rbspa.ufba.br ISSN 15199940

Tabela 4. Médias de mínimos quadrados de concentrações séricas de gama glutamina transferase (GGT), creatinina quinase e aspartato aminotransferase (AST) de vacas leiteiras mantidas a pasto suplementadas com concentrados contendo diferentes fontes proteicas

\begin{tabular}{lccccccccc}
\hline \multirow{2}{*}{ Variáveis } & \multicolumn{4}{c}{ Suplementos $^{1}$} & \multirow{2}{*}{ EPM } & \multicolumn{4}{c}{ Valor P } \\
\cline { 2 - 4 } & SPF & SPS & SPG & SPA & & Trat & Tempo & Trat*Tempo \\
\hline GGT (UI/L) & 25,01 & 25,29 & 26,78 & 26,25 & 7,16 & 0,947 & 0,014 & 0,972 \\
Creatinina quinase (UI/L) & 108,97 & 111,01 & 110,41 & 119,80 & 9,38 & 0,475 & 0,585 & 0,702 \\
AST (UI/L) & 62,44 & 59,84 & 56,84 & 54,34 & 9,10 & 0,431 & 0,254 & 0,782 \\
\hline
\end{tabular}

* Suplementos: $\mathrm{SPF}=$ resíduo de feijão; $\mathrm{SPS}=$ farelo de soja; $\mathrm{SPG}=$ farelo de girassol e $\mathrm{SPA}=$ farelo de Algodão 38\% (PB).

$\mathrm{EPM}=$ erro padrão da média.

Não se observou efeito $(\mathrm{P}<0,05)$ das fontes proteicas, dos tempos de coleta $\mathrm{e}$ nem mesmo a interação desses fatores nos níveis sanguíneos de creatinina quinase, com média de $112,13 \pm 31,72$ UI/dL (Tabela 4). A concentração sérica de creatinina permite avaliar o bom funcionamento renal, refletindo assim a adequada taxa de filtração renal (BORGES et al., 2008). Os valores de creatinina quinase observados nesse estudo estão a baixo de $130 \mathrm{UI} / \mathrm{dL}$ citados por Wittwer (2000) para bovinos saudáveis.

Não houve efeito de interação $(\mathrm{P}>0,05)$ entre as fontes proteicas utilizadas e os tempos de coleta para os níveis sanguíneos de AST. Também não se observou efeito $(\mathrm{P}>0,05)$ das fontes proteicas nos valores de AST, sendo obtido média de 58,79 $\pm 20,13 \mathrm{UI} / \mathrm{L}$ (Tabela 4). Esses valores estão dentro da variação de $34,76 \pm 10,61$ a 110,10 citados por diversos autores para vacas leiteiras saudáveis (FRASER, 1996; SOUZA, 1997; ALVES, et al., 2004; SOUZA et al., 2001).

A adequada variação dos valores séricos das enzimas GGT, CK e AST refletem que as diferentes fontes proteicas utilizadas neste estudo não comprometeram a função hepática e renal e nem mesmo ocasionou desordens musculares, podendo ser utilizas na dieta dos animais sem comprometer o seu desempenho.

As diferentes fontes proteicas resultaram em alteração dos valores sanguíneos de glicose de acordo com os tempos de coletas, sendo que estes alteraram os valores de triglicerídeos e ureia. Não foram observadas alterações para os demais metabólitos sanguíneos estudados.

\section{REFERÊNCIAS}

AEBERHARD, K.; BRUCKMAIER, R.M.; BLUM, J. Metabolic, enzimatic and endocrine status in high-yielding dairy cows. Part 2. Journal of Veterinary Medicine Series APhysiology Pathology Clinical Medicine, v.48, n.2, p.111-127, 2001.

ALVES, M.; GONZÁLEZ, F.; CARVALHO, N.; MÜHLBACH, P.; LIMA, V.; CONCEIÇÃO, T.R.; WALD, V. Feeding dairy cows with soybean by-products: effects on metabolic profile. Ciência Rural, v.34, n.1, p.239-243, 2004. 
Rev. Bras. Saúde Prod. Anim., Salvador, v.17, n.2, p.174-185 abr./jun., 2016 http://www.rbspa.ufba.br ISSN 15199940

ARRUDA, D.S.R.; CALIXTO

JUNIOR, M.; JOBIM, C.C.; SANTOS, G.T. Efeito de diferentes volumosos sobre os constituintes sanguíneos de vacas da raça holandesa. Revista Brasileira de Saúde e Produção Animal [online], v.9, n.1, p.35-44, 2008.

BOUDA, J.; OCHOA, L.N.; QUIROZROCHA, G.F. Interpretação dos perfis de laboratório em bovinos. In: GONZÁLEZ F.H.D., OSPINA H., BARCELOS J.O., RIBEIRO L.A.O. (Eds). Perfil metabólico em ruminantes: Seu uso em nutrição e doenças nutricionais. Porto Alegre: UFRGS, 2000. p. 19-22.

BUTLER, W.R. Nutritional interactions with reproductive performance in dairy cattle. Animal Reproduction Science, v.60-61, p.449-457, 2000.

CAMACHO, L.E.; BENAVIDEZ, J.M.; HALLFORD, D.M. Serum hormone profiles, pregnancy rates, and offspring performance of Rambouillet ewes treated with recombinant bovine somatotropin before breeding. Journal of Animal Science, v.90, n.8, p.28262835, 2012.

CAMPOS, R.; GONZALEZ, F.H.D.; COLDEBELLA, A.; LACERDA, L. Indicadores do metabolismo energético no pós-parto de vacas leiteiras de alta produção e sua relação com a composição do leite. Ciência Animal. Brasileira, v.8, n.2, p.241-249, 2007.

\section{CQBAL. Composição química e} bromatológica de alimentos.

Disponível em:

$<$ http://cqbal.agropecuaria.ws/webcqbal /bin/relatorios/filtroAlimentos.php> Acesso em: 20 jan.2015.
COZZI, G.; RAVAROTTO, L.;

GOTTARDO, F.; STEFANI, A.L.;

CONTIERO, B.; MORO, L.; BRSCIC, M.; DALVIT, P. Reference values for blood parameters in Holstein dairy cows: Effects of parity, stage of lactation, and season of production. Journal of Animal Science, v.94, n.8, p.3895-3901, 2011.

FATAHNIA, F.; SHAHSAVAR, A.; MIRZAEI ALAMOUTI, H.R.;

DARMANI KOHI, H.; AMANLOU, H.; AHMADI, M. Influence of starch sources in prepartum diet on colostrum quality and blood immunoglobulin concentration of calves. Iranian Journal Applied Animal Science, v.2, n.1, p.57-61, 2012.

FERGUSON, J.D.; CHALUPA, W. Symposium: interactions of nutrition and reproduction. Journal of Animal Science, v.72, p.746-766, 1989.

FONSECA, A.A.; ZANINE, A.M.; RIBEIRO, M.D.; LEONEL, F.P.; FERREIRA, D.J.; SOUZA, A.L.; SILVA, F.G.; CORREA, R.A.; CORRÊA NETO, C.R. Growth performance and blood parameters of dairy cows subjected to grazing and to a supplementary diet of bean residues. Pesquisa Agropecuária Brasileira, v.51, n.1, p.76-85, 2016.

FRASER, C.M. Manual Merck de veterinária: um manual de diagnóstico, tratamento, prevenção e controle de doenças para veterinário. 7.ed. São Paulo: Roca, 1996. 2118p.

GANDRA, J.R.; RENNÓ, F.P.; SILVA, L.F.P.; FREITAS JÚNIOR, J.E.; MATURAMA FILHO, M.; GANDRA, E.R.S.; D'ANGELO, L.S.; ARAÚJO, A.P.C. Parâmetros sanguíneos de vacas leiteiras submetidas à diferentes níveis de monensina sódica nas rações. Revista Brasileira de Saúde e Produção Animal [online], v.10, n.1, p.115-128, 2009. 
Rev. Bras. Saúde Prod. Anim., Salvador, v.17, n.2, p.174-185 abr./jun., 2016 http://www.rbspa.ufba.br ISSN 15199940

GONZÁLEZ, F.H.D.; HAIDA, K.; ZANELLA, R.; FIGUR, K. Influência da época do ano no perfil metabólico em gado leiteiro no sul do Brasil.

Arquivos da Faculdade de Veterinária da UFRGS, v.24, p.11-24, 1996.

GONZÁLEZ, F.H.D.; ROCHA, J.A. Metabolic profile variations and reproduction performance in Holstein cows of different milk yields in southern Brazil. Arquivos da

Faculdade de Veterinária da UFRGS, v.26, p.52-64, 1998.

GONZÁLEZ F.H.D. Ferramentas de diagnóstico e monitoramento das doenças metabólicas. Ciência Animal Brasileira, v.1, p.1-22, 2009.

GONZÁLEZ, F.H.D.; MUIÑO, R.; PEREIRA, V.; CAMPOS, R.; BENEDITO, J.L. Relationship among blood indicators of lipomobilization and hepatic function during early lactation in high-yielding dairy cows. The Journal of Veterinary Science, v.13, n.3, p.251-255, 2011.

HAIDA, K.S.; GONZALEZ, F.H.D.; PARZIANELLO, N.; LANGER C.; ZANOLLA N.; FIGUR K.C.; BORG, L. Estudo do perfil metabólico de um rebanho leiteiro do oeste do Paraná.

Semina: Ciências Agrárias, v.17, n.1, p.72-76, 1996.

LOHRENZ, A.K.; DUSKE, K.; SCHNEIDER, F.; NÜRNBERG, K.; LOSAND, B.; SEYFERT, H.M.; METGES, C.C.; HAMMON, H.M. Milk performance and glucose metabolism in dairy cows fed rumenprotected fat during mid lactation.

Journal of Dairy Science, v.93, n.12, p.5867-5876, 2010.
MARCONDES, M.J.; VALADARES

FILHO, S.C.; DETMANN, E.;

VALADARES, R.F.D.; SILVA, L.F.C.; FONSECA, M.A. Degradação ruminal e digestibilidade intestinal da proteína bruta de alimentos para bovinos. Revista Brasileira de Zootecnia, v.38, n.11, p.2247-2257, 2009.

MARQUES, L.T.; FISCHER, V.; ZANELA, M.B.; RIBEIRO, M.E.R.; STUMPF JUNIOR, W.; MANZKE, N. Fornecimento de suplementos com diferentes níveis de energia e proteína para vacas Jersey e seus efeitos sobre a instabilidade do leite. Revista. Brasileira de Zootecnia, v.39, n.12, p.2724-2730, 2010 .

MARQUES, L.T.; FISCHER, V.; ZANELA, M.B.; RIBEIRO, M.E.R.; STUMPF JÚNIOR, W.; RODRIGUES, C.M. Produção leiteira, composição do leite e perfil bioquímico sanguíneo de vacas lactantes sob suplementação com sal aniônico. Revista Brasileira de Zootecnia, v.40, n.5, p.1088-1094, 2011.

MARTINS, A.S.; ZEOULA, L.M.; PRADO, I.N.; MARTINS, E.M.; LOYOLA, V.R. Degradabilidade ruminal in situ da matéria seca e proteína bruta das silagens de milho e sorgo e de alguns alimentos. Revista. Brasileira de

Zootecnia, v.28, n.5, p.1109-1117, 1999.

MUNDIM, A.V.; COSTA, A.S.;

MUNDIM, S.A.P; GUIMARÃES, E.C.; ESPINDOLA, F.S. Influência da ordem e estádios da lactação no perfil bioquímico sanguíneo de cabras da raça Saanen.

Arquivo Brasileiro de Medicina Veterinária e Zootecnia, v.59, n.2, p.306-312, 2007.

NATIONAL RESEARCH COUNCIL NRC. Nutrient of requirements of dairy cattle. 7 ed., Washington, D.C.: National Academic Press, 2001. 362p. 
Rev. Bras. Saúde Prod. Anim., Salvador, v.17, n.2, p.174-185 abr./jun., 2016 http://www.rbspa.ufba.br ISSN 15199940

NIKKHAH, A.; FUREDI, C.J.; KENNEDY, A.D.; CROW, G.H.; PLAIZIER, J.C. Effects of feed delivery time on feed intake, milk production, and blood metabolites of dairy cows. Journal of Dairy Science, v.91, n.11, p.4249-4260, 2008.

PEDROSO, A.M.; SANTOS, F.A.P.; BITTAR, C.M.M.; PIRES, A.V.; MARTINEZ, J.C. Substituição do milho moído por casca de soja na ração de vacas leiteiras em confinamento.

Revista Brasileira de Zootecnia, v.36, n.5, p.1651-1657, 2007.

POGLIANI, F.C.; BIRGEL JÚNIOR, E.; Valores de referência do lipidograma de bovinos da raça holandesa, criados no Estado de São Paulo. Journal of Veterinary Research and Animal Science, v.44, n.5, p.373-383, 2007.

POSSAMAI, A.J.; DONIDA, E.R.; SORTE, E.C.B.; MELO, A.C.B.; FREIRIA, L.B.; AZEVEDO, J.B.; SILVA, P.I.J.L.R.E.; ZERVOUDAKIS, J.T. Uso de glicosímetro para determinar a glicemia de bovinos em terminação. In: CONGRESSO BRASILEIRO DE BUIATRIA, 10., 2013, Belém. Anais... Belém:

Congresso Brasileiro de Buiatria, 2013.

SOUZA, P.M. Perfil bioquímico sérico de bovinos das raças Gir, Holandesa e Girolanda, criados no Estado de São Paulo - Influência de fatores de variabilidade etários e sexuais. 1997. 168f. Tese (Doutorado em Clínica Veterinária) - Universidade de São Paulo, São Paulo.

SOUZA, R.M.; BIRGEL, E.H.; AYRES, M.C.C.; MIRANDOLA, R.M.; BIRGEL JÚNIOR, E.H. Influência dos fatores raciais na função hepática de bovinos da raça Holandesa e Jersey. In:
CONGRESSO BRASILEIRO DE MEDICINA VETERINÁRIA, 28, 2001, Salvador.Anais... São Paulo: USP, 2001.

VAN SOEST, P.J. Nutritional ecology of the ruminant. 2.ed., Ithaca: Cornell University Press, 1994. 476.

WITTWER, F. Diagnóstico dos desequilíbrios metabólicos de energia em rebanhos bovinos. In: GONZÁLEZ, F.H.D.; BARCELLOS, J.O.; OSPINA, H.; RIBEIRO, L.A.O. (Eds.). Perfil metabólico em ruminantes: seu uso em nutrição e doenças nutricionais. Porto Alegre: UFRGS, 2000. p.9-22.

Data de recebimento: $23 / 06 / 2015$

Data de aprovação: 04/04/2016 